Alen Širca

\title{
Ekfrazno pesništvo pri Romanu Melodu in Pavlu Silentiariju
}

Ključne besede: Roman Melod, Pavel Silentiarij, bizantinska literatura, ekfraza, Hagia Sofia

DOI: 10.4312/ars.11.1.63-74

Sodobno pojmovanje ekfraze, ki v zadnjih nekaj desetletjih postaja priljubljena raziskovalna tema $v$ humanistiki, je znano. Gre za dialog jezikovnega medija z vizualnim oziroma, natančneje, za retorični ali literarni govor o umetniških predmetih. Ni povsem jasno, kdaj je takšno moderno oziroma sodobno pojmovanje ekfraze nastalo. Ruth Webb meni, da je na to odločilno vplival znameniti avstrijski romanist Leo Spitzer, ki je v nekem članku v ugledni reviji Comparative Literature iz leta 1955 podal več opredelitev ekfraze, kot na primer, da je »pesniški opis slikarskega ali kiparskega umetniškega dela«, »besedna reprezentacija vizualne reprezentacije« ali kratko malo »govor o podobi« $(2009,1)$.

Kakor koli že, v tej razpravi, ki se osredinja na največjega zgodnjebizantinskega pesnika Romana Meloda, se bomo oprli na drugačno pojmovanje ekfraze, namreč na takšno, ki je skladno s pojmovanjem ekfraze v Bizancu 6. stoletja. Oprli se bomo torej na (pozno)antično opredelitev ekfraze, ki je kot prvo zgodovinsko ohranjeno pričevanje ekfraze hkrati tudi temelj za njeno moderno pojmovanje. V ospredju našega zanimanja torej ne bo - in to je treba poudariti - dandanes že povsem ustaljeno razumevanje ekfraze kot literarnega opisa kake (vizualne) umetnine, čeprav se bomo tega znotraj bizantinske literature vendarle dotaknili, temveč antično pojmovanje, ki izhaja iz helenistične retorike.

Antični pomen ekfraze je bil precej širši, kot je današnji, lahko bi rekli, da je šlo za retorično precej bolj inkluzivno pojmovanje. To je razvidno že iz samih antičnih opredelitev, ki so se ohranile v t. i. progymnasmata. Kot nakazuje že samo ime (lat. ustreznica je praeexercitamina), je šlo za preliminarne, pripravljalne retoriške vaje, namenjene urjenju govornikov. Te so se $\mathrm{v}$ antičnih retorskih šolah na široko razmahnile $\mathrm{v}$ helenistični dobi (Kennedy, 1994, 202). ${ }^{1}$ Najzgodnejšo in najbolj klasično definicijo ekfraze podaja Teon. Glasi se takole:

1 Ohranile so se samo štiri takšne progymnasmata, ki so si vsebinsko precej podobne. Poleg Teona, ki je napisal doslej najzgodnejše ohranjene takšne vaje, namreč v 1. st. po Kr., so drugi avtorji še Hermogen iz Tarza, Aftonij Antiohijski in Nikolaj Sofist. Samo Nikolaj kot možen predmet ekfraze omenja tudi umetnino, vendar to za opredelitev bistva ekfraze ni bistveno (Webb, 2009, 55). V Bizancu je bilo sicer najbolj cenjeno Aftonijevo delo, ki je, potem ko ga je Rudolph Agricola prevedel v latinščino, osvojilo tudi Zahod (Kennedy, 1994, 203). 
„Ekfraza je opisni govor [lógos periegematikòs], ki živo [enargôs] prinaša prikazani predmet pred oči. Ekfraza se lahko nanaša na osebe, dogodke ali na kraje in čase. $\aleph^{2}$

Pri tej opredelitvi sta bistvena dva elementa. Najprej gre za opisni govor, opis. Pravzaprav je prevod »opis« tu le zasilen, saj lógos periegematikós dobesedno pomeni »govor, ki (nekoga) pelje oziroma vodi okrog (nečesa)«(Webb, 1999, 65). Periegematični govor pa je vrsta pripovednega govora (diegeze). Sama grška beseda za pripoved (diégesis, diegéomai) poleg "pripovedovati« pomeni tudi »odriniti«, "odpraviti se«. Zato je treba vedno imeti v mislih korelativnosti pripovedovanja in potovanja. Latinski prevedek za periegezo kot descriptio žal te konotacije nima. Vendar bi se lahko, vsaj z modernega gledišča, vprašali, ali ekfraza kot »opisni«, periegetični govor $\mathrm{v}$ dinamiko pripovedi ne vnaša statičnosti? Ali gre tu vendarle za nekakšno zaustavljanje napredovanja pripovedi, na kar meri predpona peri-, za kroženje ali meandriranje, ki zareže v premočrtno pripovedno pot. Čeprav je, vsaj formalno gledano, med pripovedjo in opisom temeljna zareza, in sicer se pripoved nanaša na dogodke, opis, deskripcija, pa na stvari, antično pojmovanje ekfraze takšne dihotomične opredelitve razgrajuje. Ekfraza je vendarle kot nazoren opis krajev, časov, oseb, živali, rastlin, pa tudi dogodkov (!) konstitutivni element vsake pripovedi; lahko bi celo rekli, da je ancilla narrationis, kajti nobena pripoved ne more dolgo vzdržati brez opisa, brez interupcije »statičnosti« (Fowler, 1991, 26).

Druga pomembna komponenta pri antični opredelitvi ekfraze je beseda enárgeia, ki bi jo lahko prevedli kot »živost« ali »živopisnost» (lat. ustreznici sta evidentia in perspicuitas). Gre torej za govor, ki prinaša predmet živo pred oči, za nazoren govor. Takšna uporaba jezika, ki pri občinstvu omogoča nazorno predstavljanje kakega predmeta, scene ali dogodka, ima povrhu močan emocionalni učinek. Ekfrastični govor kot živ govor vzbuja poslušalčevo oziroma bralčevo domišljijsko zmožnost do te mere, da v mediju jezika naredi to, kar je odsotno, prisotno in ima zato nanj velik učinek, vtis, ki je psihološko določen in pomenljiv. Enárgeia torej meri na lastnost jezika, ki vodi onkraj besed, $\mathrm{k}$ vizualnemu, in pri tem podobo »okrasi« s sorodnimi čustvenimi asociacijami (Webb, 2009, 105).

Oglejmo si zdaj, kako je z ekfrazo v zgodnjebizantinskem pesništvu, pri Romanu Melodu. Po presoji Karla Krumbacherja, enega izmed očetov moderne bizantinistike, velja Roman Melod nič manj kot za "največjega cerkvenega pesnika vseh časov« (1897, 316). O njegovem življenju ne vemo kaj dosti. Rodil se je v Emesi (današnji Homs v Siriji) okoli leta 485, in sicer najverjetneje v judovski družini.

2 Teon, Progymnasmata II, 118; navedeno po Webb, 2009, 197. 
Najprej je služil kot diakon v krščanski skupnosti v Beritu (danes Bejrut), potem pa je za časa Anastazija I. (491-518) prišel v Carigrad, kjer je bil kot kantor določen za cerkev Marije Device. Pod Justinijanom I. je postal carigrajski dvorni himnograf. V tem času je napisal večino svojih liturgičnih pesmi (Kazhdan, 1991, III, 1807-1808; Rosenqvist, 2007, 24-26).

Pesniška oblika, v kateri je Roman pesnil, se imenuje kondakij (kontákion). Beseda izvira iz grške besede kóntaks, kar pomeni palico, okrog katere je navit zvitek. V začetku 6. stoletja pa kondakij začne označevati kitično obliko pesmi, ki je prenovila grško pesništvo, saj pomeni začetek toničnega verza, se pravi, da je v grško metrično pesništvo vpeljala akcent, naglas. Vsebinska označitev, da gre pri kondakijih za »pesniške homilije« oziroma "pridige v verzih« (Kazhdan, 1991, II, 1148), je nekoliko zavajajoča. Čeprav je podobnost s tedanjo zgodnjebizantinsko homilijo velika in je kontekst skoraj vedno liturgičen, gre vendarle bolj kot za teologijo ali pridigo v verzih za pravo pesništvo. Averincev, vodilni sodobni poznavalec zgodnjebizantinskega pesništva, namreč pravi, da Roman »ni bil ne teolog ne samo pridigar, ampak predvsem pesnik. Njegova naloga ni bila samo poučevati in pojasnjevati, temveč bolj pokazati in sugerirati. Zato je uporabljal kitično-refrensko obliko, ki v sebi že ima lik antinomičnosti: gibanje kitic je konstruktivno postavljeno nasproti nespremenljivosti vedno znova ponavljajočega se refrena« (Averincev, 2005, 302).

Legenda, ki jo pripovedujejo številni Romanovi življenjepisi, pravi, da je bil sprva povsem nenadarjen tako za petje kot za ustvarjanje verzov. Potem pa naj bi se zgodil čudež: na božično noč naj bi se mu v sanjah prikazala Božja Mati in mu dala jesti zvitek. Takrat je postal »Sladkopevec«, kot mu pravi rusko izročilo, vrhunski pevec in pesnik, ki naj bi za časa življenja sestavil okrog tisoč kondakijev (Averincev, 2005, 277). Število je verjetno pretirano, kljub temu pa opozarja na to, da je bil bržkone izjemno plodovit pesnik. Žal se je do danes ohranilo samo petinosemdeset kondakijev, ki so podpisani z njegovim imenom - in najverjetneje tudi ti niso vsi avtentični. Bizantinsko cerkveno izročilo mu pripisuje tudi avtorstvo najznamenitejše bizantinske himne, imenovane "Akatist (gr. Akáthistos hýmnos, dobesedno »himna, pri kateri se ne sedi «), ${ }^{3}$ vendar ta danes velja za anonimno delo. Zanimivo je, da Romanove himne pozneje niso bile sprejete v bizantinsko liturgijo - čeprav je sam postal svetnik in goduje 1. oktobra -, saj so kondakiji v Bizancu kmalu postali nepriljubljena pesniška oblika; zadnji veliki pisec kondakijev je bil Jožef Himnograf (Pesmopisec) v 9. stoletju. Večina Romanovih pesmi je vezana na večje liturgične praznike in tematsko črpa iz Svetega pisma, predvsem Nove zaveze. $\mathrm{V}$ njih pogosto naletimo na izrazit dialoški ustroj, zato je videti, da imamo opravka 
z nekakšnimi protodramskimi besedili, čeprav seveda ne predpostavljajo domnevne bizantinske gledališke prakse. ${ }^{4}$ Roman, ki je pisal v jasni in preprosti aticizirajoči grščini, je bil nedvomno vsestransko odličen pisec: ne samo, da je bil psihološko pronicljiv in teološko globokomiseln, temveč se njegov jezik odlikuje po mojstrski uporabi raznih besednih iger, paralelizmov, paradoksov, oksimoronov in ironije ter včasih tudi po drzni uporabi metafor.

Veliko črnila je bilo prelitega glede vprašanja, kateri so viri za to najvidnejšo zgodnjebizantinsko pesniško obliko in kateri so bili morebitni Melodovi vzori. Večina raziskovalcev ugotavlja, da je tu najverjetneje prišlo do vpliva sirskega cerkvenega pesništva, katerega vodilni predstavnik je bil Efrem Sirski (ok. 306-373). Tako naj bi bile $\mathrm{v}$ grščino prevedene Efremove himne (oziroma, natančneje, madraše, ki so formalno precej blizu bizantinskemu kondakiju), napisane $\mathrm{v}$ aramejščini, tako po miselnih vzorcih kot pri uporabi konkretnih besed ponekod skoraj identične Melodovim verzom (Wellesz, 1961, 187). Vsekakor pa je treba poudariti, da je kljub bližnjevzhodnim vplivom in podobnemu ustroju eksegetskega konteksta s poudarjeno ekshortativno noto med grškim in sirskim cerkvenim pesništvom Melod dosegel edinstveno kulturno sintezo (Van Rompay, 1993, 286).

$\mathrm{V}$ tej razpravi nas ne bo zanimalo Sladkopevčevo pesništvo na splošno, ampak si bomo ogledali nekaj odstavkov njegovih pesmi, kjer bi lahko govorili o ekfrastičnosti, kakor smo jo že uvodoma nakazali.

Eden izmed vabljivih načinov približevanja Romanovemu pesništvu je analiza tistih verzov, ki so sorodni poznejšim likovnim prikazom svetopisemskih in splošno duhovnih motivov v bizantinski ikoni. Po presoji Averinceva $(2005,233)$ je morda najvidnejši tak motiv Jezusa otroka, ki je hkrati starec. Poistenje otroka in starca v Jezusovi osebi, ki se navezuje tudi na Danielovo videnje »Staroletnega« (Dan 7,9), je namreč v zgodnjebizantinski umetnosti pomemben motiv, saj je že zelo zgodaj postal obvezen del bizantinske ikonografije. V tem pogledu je treba opozoriti na enkavstično ikono s Sinaja, ki predstavlja Mater Božjo na prestolu v družbi dveh svetih vojščakov in dveh angelov, ki jo je mogoče datirati celo v 5. stoletje in bi jo, če je tako zgodnja datacija pravilna, morda lahko imeli celo za istodobni pojav z Romanovim liturgičnim pesništvom.

Pri Romanu na pesniški izraz otroka starca naletimo v znamenitem božičnem kondakiju. Tu je Jezus kot novorojeno dete hkrati opevan kot predvečni Logos; gre za paradoksno formulacijo, ki med drugim sugerira, da je $\mathrm{v}$ jasli položeno dete vendarle

4 Kljub številnim poskusom, da bi dokazali obstoj bizantinske dramatike, je po mnenju večine strokovnjakov to iluzorno. Bizanc pač gledališča ni poznal, razen morda v zelo zgodnji dobi. Cerkev ga je namreč kmalu prepovedala kot nemoralno ustanovo. Kljub temu se zdi, da je večino dramskih prvin ohranila ravno liturgija (Kazhdan, 1991, III, 2031). 
tudi starejše od neba in zemlje ter je zato na neki način tudi starec, čeprav ta beseda ni uporabljena. Takole se glasi odpev omenjenega božičnega kondakija:

He parthénos sémeron tòn hyperoúsion tíktei,

kaì he gê tò spélaion tô aprosíto proságei.

ángeloi metà poiménon doksologoûsi,

mágoi dè metà astéros hodoiporoûsi:

di‘ hemâs gàr egennéthe

paidíon néon, ho prò aiónon theós (Romanos le Melode, II, 1965, 50).

Danes Devica rojeva nadbitnostnega,

in zemlja ponuja votlino Nedosegljivemu.

Angeli s pastirji pojejo hvalnice,

modri potujejo z zvezdo:

kajti za nas je rojen,

novorojenček, predvečni Bog. ${ }^{5}$

Ta refren $\mathrm{v}$ marsičem nakazuje bistvo Romanovega pesništva. Ob pomoči paradoksov in antitez skuša izrekati to, kar je $\mathrm{v}$ temelju neizrekljivo, in jezikovno dajati videti nevidljivo. Podoba votline - in ne hleva, kot smo vajeni na Zahodu -, ${ }^{6}$ ki sprejema oziroma zajema, zaobsega dojenčka, ki je v resnici hkrati neskončni, nedosegljivi in nezaobjemljivi Bog, zaostruje začetni paradoks device, ki rojeva »nadbitnostnega Boga «. Antitetični prikaz se potem stopnjuje v druženju »visokega « $\mathrm{z}$ »nizkim«: angeli namreč družno prepevajo z navadnimi pastirji in »magi«. To pomeni, da modreci, ki prihajajo iz poganskih dežel, ne vztrajajo več pri lastni modrosti, ampak se dajejo voditi zvezdi. Sklepna vrstica paidion néon, ho prò aiónon theós, pa antitetično "pripoved « pripelje do vrhunca.

Če bi tu o ekfrazi lahko govorili samo pogojno, saj je za pravo ekfrazo »opis dogodka " morda nekoliko skop, redkobeseden, pa v kondakiju o pomoru nedolžnih otrok naletimo na daljši periegetični opis, ki se poleg tega, da predstavlja izjemno redek pesniški motiv v vzhodnem cerkvenem pesništvu, odlikuje po malone grozljivem

5 Prevod je karseda dobeseden in zato povsem prozen, se pravi, da ne sledi ritmično-evfoničnemu ustroju izvirnika, in sicer zato, da bi lahko čim bolj sledili semantični podobi izvirnika. Tako ravnam tudi pri drugih prevodih. Za bolj pesniški prevod tega odpeva glej Kocijančič, 2000, 43: »Devica danes rojeva Nadbitnostnega / in zemlja daje zavetje Nedostopnemu / angeli slavijo skupaj s pastirji / in modri potujejo z zvezdo, / ker se za nas je rodil / novorojenček, pred vsemi veki Bog.»

6 Roman se pri tem opira na starokrščansko izročilo, ki izhaja iz nekanoničnih spisov; predvsem je tu v ozadju apokrifni Jakobov protoevangelij oziroma Jakobov evangelij o Jezusovem otroštvu, ki naj bi nastal ob koncu 2. stoletja. Tu je za razliko od kanoničnih evangelijev o Jezusovem rojstvu rečeno takole: "Našel je [Jožef] tam votlino in jo [Marijo] peljal vanjo, pustil pri njej svoja sinova in šel ven, da poišče babico Hebrejsko v betlehemski deželi. [...] Šla je [babica] z njim in stopila sta na kraj votline. Temen oblak je obsenčeval votlino. [...] Oblak se je pri priči umaknil in v votlini se je prikazala velika luč, tako da je oči niso mogle vzdržati. Čez čas se je luč umaknila in prikazal se je novorojenec (Zgodnjekrščanski spisi, 2015, 1158). 
naturalizmu. Pokol betlehemskih otrok, ki jih je dal pobiti Herod I. v strahu, da novorojeni Jezus ogroža njegov prestol, o čemer beremo v Matejevem evangeliju (Mt 2,16-18), je Roman izvirno obdelal in se svojsko poglobil v detajle pokola, ki nedvomno učinkujejo ekfrastično, saj ponujajo živ opis dogodka, ki ga svetopisemska pripoved samo nakaže. V 14. ojkosu (kitici) Roman svoj »krvavi« realizem pripelje do vrhunca, ko pesniško prikazuje odsekane glave dojencev, ki so še zmeraj prisesane na materine dojke:

Eni so, grozljivo prebodeni, izdihnili, druge so presekali na dvoje, spet drugim so odsekali glave, ko so še sesali dojko svoje matere in se napajali z mlekom, in sicer tako, da so svete glavice otročičev visele na prsih in so njihovi mehki zobki še vedno v ustih držali prsne bradavice (ibid., 221).

Tretji primer Romanove ekfrastične veščine se dotika zgodovine Carigrada in njegove arhitekture. V kondakiju o potresu in požaru v Carigradu - to je tudi edini kondakij, ki nima liturgičnega značaja - Melod opeva tri nesreče, ki jih je, kakor sam teološko razlaga, Bog prizadejal Carigradu zaradi (pre)velike grešnosti njegovih prebivalcev. Gre za potres, sušo in požar. Ti dogodki so zgodovinsko preverjeni. Dejansko je bilo med letoma 526 in 530 v Carigradu več potresov, potem je leta 530 nastopila huda suša, nazadnje, kot kulminacija vseh nesreč, pa je opisan požar, ki se nanaša na znamenit upor Nika januarja 532 (Louth, 2005, 109). Pri tem uporu, ki je bil verjetno najnasilnejši upor v vsej zgodovini bizantinskega Carigrada, je razjarjena množica, ki so jo nahujskale proticesarske stranke, skušala strmoglaviti Justinijana I., pri tem pa se je razvnel velik požar, ki naj bi uničil skoraj polovico mesta in pri katerem naj bi izgubilo življenje na tisoče ljudi.

Roman v pesniški ekfrazi opiše požar, katerega uničujočo moč paradoksno večajo drugi naravni elementi, kot sta veter in naraslo morje, ki, namesto da bi učinkovalo kot gasilo, onemogoča beg in je dodaten vzrok nesreče:

Ogenj je kakor oblak besnel po vsem zraku

in se bliskal in použival vse; in strašil je, ne da bi se ustavil pred mnogimi nasprotnimi vetrovi

in ne da bi se bal vode.

Vrh tega pa so se vzdignile vode morja.

Roke ljudi niso mogle pomagati.

Ogenj jim je zmagoslavno kljuboval

in tudi morje samo se je bojevalo zoper nje,

saj je oviralo tiste, ki so skušali bežati:

in zato so klicali večno življenje (Romanos le Melode, V, 1981, 486 in 488). 
V nadaljevanju Melod pripoveduje, da je po požaru nad mesto legla velika žalost. Večina mesta je bila eno samo pogorišče. Tudi najlepšim cerkvam ni bilo prizaneseno, tako cerkev svete Irene (Hagia Irene) kot svete Sofije (Hagia Sofia) sta bili porušeni. Melod ju metaforično oriše kot dva kadavra, ki ležita na tleh in gnijeta: »Njuna veličastna lepota je bila polna trohnobe [pléres saprías] (ibid., 492). A na mesto je vendarle kmalu posijalo sonce, sonce Božjega usmiljenja. Goreče prošnje ljudstva in vladarja so bile uslišane. Iz žalostno propadajočih ruševin so vstale nove cerkve. Kondakij se izteče v hvalnico Justinijanu, čigar dela po Melodovem spevu niso samo "velika, sijoča in vredna občudovanja«, ampak celo "presegajo dela kraljev preteklih časov«, zato ga Melod primerja s Salomonom in Konstantinom. Justinijan je namreč upor kmalu zadušil - tudi s pomočjo znamenitega vojskovodje Belizarja - in v kratkem času obnovil mesto, še posebno veličastno pa je obnovil Hagio Sofio. Melod v novi baziliki, ki je bila večja in razkošnejša od prejšnje ter je pomenila nekakšno spravo oziroma zavezo z Bogom, vidi nič manj kot podobo nebes oziroma Božji prestol:

Ho oîkos dè autòs ho tês ekklesías

en tosaúte aretê oikodomeîtai

hos tòn ouranòn mimeîsthai, tòn theîon thrónon,

hòs kaì paréchei zoèn tèn aiónion (ibid., 496).

Stavbo cerkve

s tako so umetelnostjo zgradili,

da posnema nebesa, Božji prestol,

ki daje večno življenje.

Zgodovinsko gledano je tu omenjena že tretja stavba te znamenite bazilike, ki je tedaj dobila podobo, kakršna se je bolj ali manj ohranila do danes. Nova bazilika je bila pod vodstvom arhitektov Antemija iz Tral in Izidorja iz Mileta zgrajena v nekaj manj kot šestih letih. 27. decembra 537 so namreč z velikim pompom proslavili njeno posvetitev. S to cerkvijo je Justinijan za tisočletje, vse do zidave nove bazilike sv. Petra v Rimu, krščanstvu postavil največji arhitekturni objekt (Lilie, 1999, 42).

Tu, kjer se Romanova arhitekturna ekfraza konča, se nadaljuje neka druga ekfraza Hagie Sofie, katere avtor je bizantinski pesnik Pavel Silentiarij (Paûlos ho Silentiários, $\dagger$ okoli 580). Ta je spisal daljšo pesnitev v heksametrih (imenovano kar Ekphrasis ali tudi Descriptio ecclesiae Sanctae Sophiae), ki je, gledano z merili sodobno pojmovane ekfraze, verjetno prva "prava« bizantinska ekfraza. Pesnitev je nastala ob ponovni posvetitvi bazilike pod patriarhom Evtihijem, 23. decembra 562. Med letoma 537 in 562 se je namreč v Carigradu zvrstilo še nekaj potresov in v enem izmed njih se je 7. maja 558 zrušila kupola. Justinijan je takoj ukazal obnovo, pri čemer je bila nova, rahlo eliptična kupola približno sedem metrov višja od prejšnje (Whitby, 1985, 216; Kazhdan, 1991, II, 893; Schibille, 16). 
Silentiarijeva dokaj obsežna ekfraza cerkve Svete Sofije se začne z opisom vzhodne apside, ekseder in polkupol ter se nadaljuje $\mathrm{z}$ opisom zahodne strani stavbe, pri tem pa so poudarjene tako vzhodno-zahodne kot vertikalne osi cerkve. $\mathrm{Ob}$ pomoči tipično ekfrastične strategije periegeze svojemu občinstvu pomaga vizualizirati specifiko svetega prostora. Jasno je, da tu nikoli ne gre za goli opis, descriptio, ampak za živopisno jezikovno ponavzočanje "živega svetišča (naós empsychós), za čutno-čustven sinestetični govor o kompleksni arhitekturi, torej za ekfrazo (ibid., 19).

Najznamenitejši je tisti del Pavlove ekfraze, ki opisuje novo kupolo. Pavel pri tem pričara temeljno zadržanje, v katero vpeljuje ekfraza, namreč čudenje (gr. thâuma); vzklika, »kako je vse oblečeno v sijaj« in kako vse »osuplja oko« (Fletcher, Carne-Ross, 1965, 564). Čudenje, osuplost pa je samo hrbtna stran občutja lepote, ki je kratko malo neizrekljiva: »Besede ne morejo opisati te večerne jasnine« (ibid.). Sledi detajlirani opis kupole, ki se čedalje bolj metaforizira ter se hkrati prepleta $\mathrm{z}$ mitološkimi referencami in reminiscencami. Naposled pa se antitetika svetlobe in teme, ki je konstitutivna podlaga celotne ekfraze, izteče v priznanje zmagoslavja veličastne svetlobe: »Tako nočni ognji krožijo skoz svetišče / in se iskrijo z radostnim bleskom. [...] Tema je izgnana [phygàs d' apelaúnetai órphne] « (ibid., 565).

Luč, svetloba, ki jo Pavel izkuša in daje videti, ni nekaj, kar bi bilo v sami stavbi kot nekakšen dodatek ali celo kot poseben učinek, ampak gre za prvino, ki je integralni del same stavbe, konstitutivni arhitekturni element. Poleg tega, in to je najpomembneje, svetloba tu dobi teološko sporočilnost, se pravi, da ni samo estetski medij, ampak tudi epifanični fenomen, snovna presojnost, v katero se lahko naseli presežna Božja svetloba. Izkušnja te svetlobe pa je lahko transformativna, gledalca (poslušalca/bralca) anagogično vpeljuje k odprtju za transcendenco. V tem pogledu je bizantinska estetika hkrati mistika, in sicer mistika luči.

Razlika med Melodovo in Silentiarijevo ekfrazo je na dlani. Če gre pri zadnjem za ekfrazo, ki izhaja iz estetske in teološke izkušnje arhitekture, v katero si prizadeva vpeljati tudi svoje občinstvo prek bogate jezikovne ornamentalike, ki bi ji ponekod lahko celo rekli baročna (Macrides, Magdalino, 1988, 53), je Romanova ekfrastika $\mathrm{v}$ navezavi na biblično pripoved precej bolj skromna in zadržana. To je seveda tudi primerneje specifičnosti njegove zvrsti, namreč liturgičnega pesništva, ki v eksegetskem kontekstu ne ponuja daljšega umskega opazovanja določene predmetnosti, ki bi se naposled lahko razvilo v motrenje, kontemplacijo, kakor pri Silentiariju, ampak s hitrimi zamahi pripovednega verza daje nenadoma uzreti misterij neizrekljivega in nevidljivega. Vsekakor pa je obema avtorjema skupna bizantinska estetika, ki se ne 
more nikoli zadovoljiti z literarnim ali splošno umetniškem prikazovanjem na zgolj snovni ravni, saj je dinamična igra imanence in transcendence na "površini« besedila, ikone, svetišča zanjo temeljna.

Prav takšno estetiko pa lahko zelo dobro osvetli ekfraza, kakor so jo razumeli antični retoriški učbeniki. Čeprav je antično pojmovanje ekfraze veliko splošnejše in ohlapnejše od sodobnega, lahko vendarle ponuja izhodišče za plodne interpretativne spodbude pri raziskovanju predmoderne literature. Tako pojmovana ekfraza, ki usmerja pozornost na zmožnost za vizualizacijo stvari, krajev, oseb in dogodkov ter pri recipientu sproža raznovrstne čutno-čustvene odzive, vendarle lahko vpeljuje tudi v nesnovno, duhovno in presežno. Zev, ki je med besedami in podobami, med jezikom in vizualnim, lahko namreč kaže tudi na neko drugo, še bolj temeljno zev, na zev med snovnim in duhovnim, človeškim in Božjim. Moment neizrekljivega, nadjezikovnega pri ekfrazi ni samo most do (zunajjezikovnega) vizualnega in s tem intermedialnega, ampak tudi do transmedialnega, če dopustimo možnost, da je lahko referent ekfraze onkraj vsakršnega medija (Bartsch, Elsner, 2007, vi). Prav na ta način pa lahko ekfraza postane odlikovani način izrekanja neizrekljivega in prikazovanja neprikazljivega.

\section{Bibliografija}

Averincev, S. S., Poetika zgodnjebizantinske literature, Ljubljana 2005.

Bartsch, Sh., Elsner, J., Introduction: Eight Ways of Looking at an Ekphrasis, Classical Philology 102.1, 2007, str. I-VI.

Fletcher, I., Carne-Ross, D. S., Ekphrasis: Lights in Santa Sophia, from Paul the Silentiary, Arion 4.4, 1965, str. 563-581.

Fowler, D. P., Narrate and Describe: The Problem of Ekphrasis, The Journal of Roman Studies 81, 1991, str. 25-35.

Kazhdan, A. P. in dr. (ur.), The Oxford Dictionary of Byzantium, 3. zv., New York, Oxford 1991.

Kennedy, G. A., A New History of Classical Rhetoric, Princeton 1994.

Kocijančič, G. (ur.), Atos: na meji zemlje in neba (antologija grške krščanske poezije), Ljubljana 2000.

Krumbacher, K., Geschichte der byzantinischen Literatur von Justinian bis zum Ende des oströmischen Reiches, München 1897.

Lilie, R. J., Byzanz: Geschichte des oströmischen Reiches 326-1453, München 1999.

Louth, A., The Eastern Empire in the Sixth Century, v: The New Cambridge Medieval History: zv. 1, c.500-c.700 (ur. Fouracre, P.), Cambridge 2005, str. 93-117. 
Macrides, R., Magdalino, P., The Architecture of Ekphrasis: Construction and Context of Paul the Silentiary's Poem on Hagia Sophia, Byzantine and Modern Greek Studies 12, 1988, str. 47-82.

Petersen, W. L., The Dependence of Romanos the Melodist Upon the Syriac Ephrem: Its Importance for the Origin of the Kontakion, Vigiliae Christianae 39, 1985, str. $171-187$.

Romanos le Melode, Hymnes (ur. Grosdidier de Matons, J.), 5. zv., Pariz 1964-1981.

Rosenqvist, J. O., Die byzantinische Literatur Vom 6. Jahrhundert bis zum Fall Konstantinopels 1453, Berlin, New York 2007.

Schibille, N., Hagia Sophia and the Byzantine Aesthetic Experience, Farnham 2014.

Van Rompay, L., Romanos le mélode, un poète syrien à Constantinople, v: Early Christian Poetry (ur. den Boeft, J., Hilhorst, A.), Leiden 1993, str. 282-296.

Webb, R., The Aesthetics of Sacred Space: Narrative, Metaphor, and Motion in »Ekphraseis« of Church Buildings, Dumbarton Oaks Papers 53, 1999, str. 59-74.

Webb, R., Ekphrasis, Imagination and Persuasion in Ancient Rhetorical Theory and Practice, Farnham 2009.

Wellesz, E., A History of Byzantine Music and Hymnography, Oxford 1961.

Whitby, M., The Occasion of Paul the Silentiary's Ekphrasis of S. Sophia, The Classical Quarterly, New Series 35.1, 1985, str. 215-228.

Zgodnjekrščanski spisi (ur. slov. izdaje Kocijančič, G., Snoj, V.), Celje, Ljubljana 2015. Akatist, prevedla F. Žakelj, G. Kocijančič, v: Tretji dan: krščanska revija za duhovnost in kulturo 29.10, 2000, str. 80-85. 


\section{Alen Širca \\ Ekfrazno pesništvo pri Romanu Melodu in Pavlu Silentiariju}

Ključne besede: Roman Melod, Pavel Silentiarij, bizantinska literatura, ekfraza, Hagia Sofia

Članek o ekfrazi pri Romanu Melodu se opira na pojmovanje ekfraze v kontekstu bizantinske retorike in literature. V skladu s takšnim pojmovanjem, ki je v temelju enako starogrški retoriški teoriji in praksi, kakor jo najdemo v retoriških učbenikih, imenovanih Progymnasmata, je najpreprostejša opredelitev ekfraze takšna, da gre za govor, ki prinaša svoj predmet živo pred oči. Tako je jasno, da je sedanja opredelitev ekfraze kot pesniškega opisa slikovne, kiparske ali arhitekturne umetnine izrazito moderna.

Po uvodnem razčiščenju glede terminologije članek obravnava ekfrazo pri Romanu Melodu, slavnem bizantinskem himnografu iz 6. stoletja, ki je avtor številnih kondakijev. Tu gre za nekakšno liturgično himno, ki je znana po številnih pesniških strategijah in velja za vrhunec bizantinske poezije. Romanova raba ekfraze v bibličnem kontekstu je vendarle na neki način zadržana. Toda $z$ naturalističnim opisom pokola nedolžnih otrok, ki presega poročilo iz Matejevega evangelija, in zlasti s tematizacijo na novo zgrajene Hagie Sofie, ki jo plastično imenuje tudi Božji prestol, Roman vendarle postavi vodilni ton bizantinski ekfrazi.

Druga arhitekturna ekfraza prihaja od nekega drugega bizantinskega pesnika iz 6. stoletja, Pavla Silentiarija. Njegovo najslovitejše delo je Descriptio ecclesiae Sanctae Sophiae. Še posebno ob opisu kupole Hagie Sofie, nekdaj največje cerkve krščanstva, ki se opira na antitetiko svetlobe in teme, spoznamo, da svetloba rabi za epifanično izkušnjo: Hagia Sofia postane snovno izkazovanje Božjega razodetja. Ekfraza tako pri Romanu kot pri Pavlu Silentiariju postane retoriško sredstvo za izrekanje neizrekljivega. 
Alen Širca

\section{Ekphrastic Poetry in Roman the Melodist and Paul the Silentiary}

Keywords: Romanos the Melodist, Paul the Silentiary, Byzantine Literature, Ekphrasis, Hagia Sophia

The article about ekphrasis in Romanos the Melodist is based on the concept of ekphrasis in the context of Byzantine rhetoric and literature. In accordance with such a conception, which is basically the same as in ancient Greek rhetorical theory and practice, as explained in rhetorical textbooks, called progymnasmata, the simplest definition of ekphrasis is a speech that makes the subject matter vivid to the audience. As such, the current definition of ekphrasis, as the poetic description of a pictorial, sculptural or architectural work of art, is decidedly modern.

After the introductory clarifications of the terminology, this article addresses the ekphrasis of Romanos the Melodist, the famous sixth-century Byzantine hymnographer who is the author of numerous kontakion. These can be considered as a kind of liturgical hymn, known for a number of poetic strategies, and are recognised as the pinnacle of Byzantine poetry. Romanos' use of ekphrasis in a biblical context is somewhat restrained. However, with the example of the naturalistic description of the Massacre of the Innocents, one that goes beyond the account in the Gospel of Matthew, and especially the thematization of rebuilding the Hagia Sophia, which is termed the Throne of God, Romanos sets the tone for Byzantine ekphrasis.

A further architectural ekphrasis comes from another sixth century Byzantine poet, Paul the Silentiary. His most well-known work is the Descriptio ecclesiae Sanctae Sophiae. In particular in his description of the cupola of what was once the biggest church in Christendom, the Hagia Sophia, which is based on the interplay between light and darkness, we recognize that the phenomenon of light serves as an epiphanic experience: the Hagia Sophia thus becomes the material manifestation of divine revelation. Therefore, in Romanos, as in Paul, ekphrasis becomes a rhetorical device for expressing the unspeakable. 